\title{
RESIDUAL STRESS OF WELDED I SECTIONS FABRICATED FROM HIGH PERFORMANCE STEEL: EXPERIMENTAL INVESTIGATION AND MODELLING
}

\author{
Yong-Lei $\mathrm{Xu}^{1}$, Yong-Jiu Shi ${ }^{* *}$, Yi-Ran $\mathrm{Wu}^{1}$ and Ling-Ye Meng ${ }^{1}$
}

Key Laboratory of Civil Engineering Safety and Durability of China Education Ministry, Department of Civil Engineering, Tsing hua University, Beijing 100084, P.R. China

*(Corresponding author: E-mail: shiyj@tsinghua.edu.cn)

\section{A B S T RACT}

An experimental study was presented to investigate the magnitude and distribution of residual stresses in welded I sections fabricated from a new type of high performance steel with high strength as well as improved fire and corrosion resistance. The residual stress of three I sections with various width-thickness ratios was measured by using sectioning method and more than 2000 original readings were obtained. The effects of width-thickness ratio and interaction of residual stress in the flange and web were clarified. It was found that compressive residual stress was strongly correlated with sectional dimensions, while tensile residual stress at the weld region or flange edge was less correlated with them. In addition, no interaction between the residual stress in the flange and web was identified. Based on the test results, a distribution model of residual stress was proposed which could well represent the experimental results. Finally, the magnitude of residual stresses in welded I sections fabricated from this new type of high performance steel was compared with that of high strength steel.

\section{AR T I C L E H I S T O R Y}

\begin{tabular}{|c|c|}
\hline Received: & 01 October 2017 \\
\hline Revised: & 21 November 2017 \\
\hline Accepted: & 13 December 2017 \\
\hline
\end{tabular}

K E Y W O R D S

WGJ steel;

Residual stress;

Welded I sections;

Sectioning process

Modeling

\section{Introduction}

Residual stress in structural steel members is induced by non-uniform heat input during manufacturing, fabricating and welding process [1]. As one of the most important initial imperfections for welded steel members, it has significant effects on the loading capacity, especially the buckling capacity, because of premature yielding and reduction of section stiffness.

In order to understand the magnitude and distribution of residual stresses, extensive investigations were conducted on conventional strength steel (CSS) sections [2-7], including rolled or welded sections and plates. Based on previous investigations, steel structural design specifications such as Eurocode 3 [8, 9], ANSI/AISC 360-10 [10], and Chinese code GB 50017-2003 [11, 12] have specified some models or calculation methods to represent the residual stress.

However, the models proposed by previous investigations and existing design specifications may not be applicable to high strength steel (HSS) or high performance steel (HPS) members, which have been increasingly applied in recent years [13]. The main considerations are as follows: (1) The material properties and the manufacturing process for HSS or HPS members are different with CSS; (2) Since the yield strength of HSS or HPS is higher, the ratio of tensile residual stress at the welding region to the yield strength of steel material may be less than that of CSS; (3) Most of the current models has not taken into account the effects of section dimensions.

Since the effect of residual stress on mechanical performance is more important for welded sections than rolled ones, and I sections are widely adopted in steel buildings, numerous researches on residual stress of HSS and HPS welded I sections have been carried out.

Rasmussen and Hancock [14, 15] conducted a series of experiments to obtain the compressive residual stress of 4 welded I sections fabricated of 690 MPa HSS. Then 4 welded I sections fabricated of $700 \mathrm{MPa}$ HSS, designated as $\mathrm{D}$ and $\mathrm{B}$, were examined by Beg and Hladnik [16]. It was found that the compressive residual stress in the flange was $0.09 f_{\mathrm{y}}$ for section $\mathrm{B}$ and $0.14 f_{\mathrm{y}}$ for section D.

In 2012, Wang et al. [17] investigated the magnitude and distribution of residual stresses of 3 flame-cut welded I-section columns with a nominal yield strength of $460 \mathrm{MPa}$ and different section dimensions. Test results showed that the compressive residual stress in the flange would decrease and tensile residual stress at the flange edge would increase when the width-thickness ratio of the flange increased. Ban et al. [18] conducted an experimental investigation to quantify the residual stress in $460 \mathrm{MPa}$ steel welded I sections by using sectioning method. The magnitude and distribution of both compressive and tensile residual stresses were obtained, and a distribution model for the residual stress of $460 \mathrm{MPa}$ HSS welded I sections was proposed based on test data obtained from 8 different sections. Ban [19] proposed a versatile model to estimate the magnitude and distribution of residual stresses, which was applicable to welded I sections and box sections fabricated from steel with various strength.
Chen [20] applied the blind-hole method to test the residual stress of flamecut welded I sections fabricated from a new type of HPS designated as GJ steel which was widely used in landmark buildings like National Olympic Stadium (Birds Nest) and new CCTV Headquarters in China. Yang et al. [21] presented an experimental investigation on the residual stress in welded I sections made of $345 \mathrm{MPa}$ GJ steel by using sectioning method. The test results indicated that the distribution of residual stresses for $345 \mathrm{MPa}$ GJ steel members had a similar profile with that for CSS, but the peak tensile and compressive residual stresses in the flange were much lower than those given by existing models. Qiu et al. [22] designed and manufactured 7 flame-cut welded I-section columns fabricated from $550 \mathrm{MPa}$ GJ steel plates. It was found that tensile residual stress at welding regions was less than actual yield strength of GJ steel (624 MPa), and compressive residual stress in flanges and webs decreased as the widththickness ratio increased. Yang et al. [23] focused on the residual stress of flame-cut welded I sections made of $460 \mathrm{MPa}$ GJ steel. 8 full scale I sections welded by flame-cut $460 \mathrm{MPa}$ GJ steel plates including 5 doubly symmetric sections and 3 singly symmetric sections were tested. Li et al. [24, 25] proposed a numerical procedure for sectional analysis and suggested a method to account for residual stress and geometric imperfections separately and independently. The approach could be applied to design HSS members.

A new type of HPS, designated as WGJ steel, with high strength as well as improved fire and corrosion resistance, was recently developed by Wuhan Iron and Steel (Group) Company. This type of steel will be widely used in the near future because of its excellent mechanical properties, especially under fire and corrosion conditions. Though there were some research publications and design guides on the loading capacity of columns and beams under fire or corrosion conditions, residual stress in welded I sections made of fire-resistant and weather-resistant steel with higher yield strength was not investigated yet. The magnitude of residual stresses in welded I sections fabricated from WGJ stee may not be precisely obtained by applying traditional models presented before, because of its special material properties.

This paper presents an experimental program to investigate the residual stress distribution of welded I sections fabricated from flame-cut WGJ steel plates. The sectioning method was employed to quantify longitudinal residual stress. I sections were characterized by various width-thickness ratios of flanges and webs. Based on the experimental results, a model to identify the magnitude and distribution of residual stresses was proposed and validated for WGJ steel welded I sections. This model will provide supportive information to the design and analysis of columns and beams fabricated of WGJ steel.

The distinct feature of this investigation is establishing a model to identify the magnitude and distribution of residual stresses in welded I sections fabricated from a new type of high performance steel. In addition, the magnitude of residual stresses in WGJ steel I sections was compared with that in HSS sections. The comparison indicated that the negative effect of residual stress in steel members could be reduced by applying WGJ steel. 


\section{Experimental program}

\subsection{Test specimens}

3 welded I-section specimens fabricated from WGJ steel in this experimental program, were summarized in Table 1. Sectional geometric parameters are illustrated in Figure 1 , where $b_{\mathrm{f}} / t_{\mathrm{f}}$ and $h_{0} / t_{\mathrm{w}}$ denote the widththickness ratios of the flange and the web respectively. Specimens were all $1000 \mathrm{~mm}$ in length and had different width-thickness ratios 法 of the flange and web. All components of WGJ steel plates were flame-cut and built-up by automatic submerged arc welding with H08MnMoA welding wire and SJ101 welding flux. The fillet weld size $\left(h_{\mathrm{f}}\right)$ was $8 \mathrm{~mm}$ for all specimens.

Before the automatic submerged-arc welding process, the welding flux was pre-heated for one hour at about $300^{\circ} \mathrm{C}$ in order to remove the water in it. As is known, water $\left(\mathrm{H}_{2} \mathrm{O}\right)$ is decomposed into hydrogen $\left(\mathrm{H}_{2}\right)$ and oxygen $\left(\mathrm{O}_{2}\right)$ under high temperature, which results in weld defect.

Based on practical experience and design specifications, $10 \mathrm{~mm}$ steel plates in this investigation did not need pre-heating because of small thickness and large coefficient of thermal conductivity. In contrast, when the thickness of a steel plate is over $40 \mathrm{~mm}$, it needs pre-heating before welding to reduce nonuniform heat input during the welding process, which leads to inhomogeneous crystalline structure of steel and residual stress in structural steel members.

Post-heating was conducted after welding in order to relieve residual stress and reduce the deformation of I sections. The temperature of post-heating was under $800^{\circ} \mathrm{C}$.

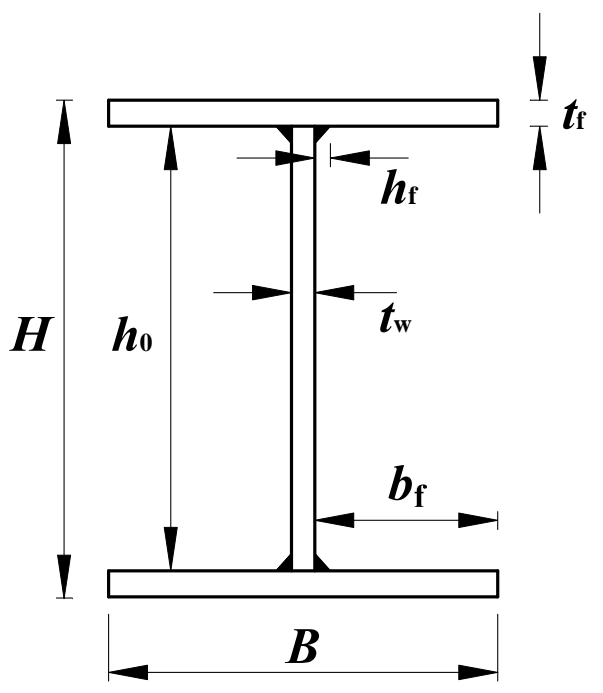

Fig. 1 Schematic diagram of the I section specimen

Table 1

Specimen section dimensions

\begin{tabular}{ccccccc}
\hline $\begin{array}{c}\text { Specimen } \\
\text { label }\end{array}$ & $H(\mathrm{~mm})$ & $B(\mathrm{~mm})$ & $t_{\mathrm{f}}(\mathrm{mm})$ & $t_{\mathrm{w}}(\mathrm{mm})$ & $b_{\mathrm{f}} / t_{\mathrm{f}}$ & $h_{0} / t_{\mathrm{w}}$ \\
\hline RI1 & 120 & 80 & 10 & 10 & 3.5 & 10 \\
RI2 & 220 & 125 & 10 & 10 & 5.75 & 20 \\
RI3 & 300 & 200 & 10 & 10 & 9.5 & 28 \\
\hline
\end{tabular}

\subsection{Main sections}

To obtain the mechanical and fire-resistant properties of WGJ steel, material tests at ambient temperature and elevated temperature were conducted. The elastic modulus of WGJ steel at ambient temperature obtained from material tests would be used to calculate the residual stress, after the residual strain was measured.

As is known, the yield strength and elastic modulus of steel reduce significantly under high temperature during welding process, especially for steel near the junction of the flange and web. WGJ steel was manufactured to be fireresistant, so mechanical properties of WGJ steel under high temperature would be quite different from those of CSS. In addition, the residual strain and stress in structural steel members after welding may be related to the mechanical properties under high temperature during welding process. Thus, residual stress of WGJ steel I sections may be different from that of CSS I sections. Material properties of WGJ steel at elevated temperatures were tested in this study.

Tension coupons were prepared and tested according to Chinese standard
$\mathrm{GB} / \mathrm{T} 228.2-2015$ [26]. Temperature conditions in the tests were $20^{\circ} \mathrm{C}, 100^{\circ} \mathrm{C}$, $200^{\circ} \mathrm{C}, 300^{\circ} \mathrm{C}, 400^{\circ} \mathrm{C}, 500^{\circ} \mathrm{C}, 600^{\circ} \mathrm{C}, 700^{\circ} \mathrm{C}, 800^{\circ} \mathrm{C}$. Once specimens were heated to the specified temperature, a duration of 10 minutes was maintained for the temperature to stabilize. Three coupons were tested under each temperature condition, while the yield strength, ultimate strength, initial elastic modulus and entire stress-strain curves were measured.

Material test results showed that the $0.2 \%$ offset yield strength of WGJ steel at ambient temperature $\left(f_{0.2}\right)$ was $433.8 \mathrm{MPa}$, and the initial elastic modulus $(E)$ was $196533 \mathrm{MPa}$, which will be used to determine the residual stress of welded I sections. The stress-strain curves shown in Figure 2 indicate that there are no visible yielding plateaus for WGJ steel under any temperature, which shows typical nonlinearity[27].

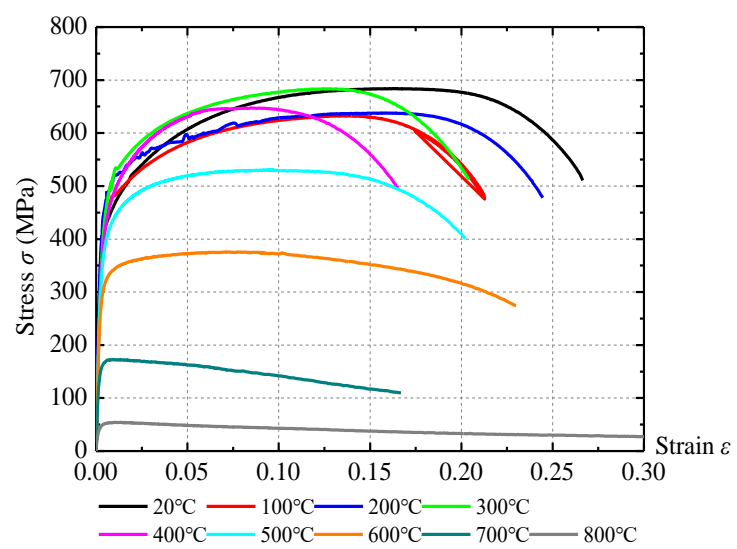

Fig. 2 Stress-strain curves of the tension coupon at different temperatures

Reduction factors can be used to describe the effect of temperature on the strength and elastic modulus of steel. For yield strength, the reduction factor $f_{0.2, \mathrm{~T}} / f_{0.2, \text { normal }}$ is defined as the ratio of $0.2 \%$ offset yield strength at different temperatures $\left(f_{0.2 \mathrm{~T}}\right)$ to that at ambient temperature $\left(f_{0.2 \text { normal }}\right)$. Similarly, the reduction factor $E_{\mathrm{T}} / E_{\text {normal }}$ is defined as the ratio of initial elastic modulus at different temperatures $\left(E_{\mathrm{T}}\right)$ to that at ambient temperature $\left(E_{\text {normal }}\right)$.

The $0.2 \%$ offset yield strength at $600^{\circ} \mathrm{C}$ was $301.0 \mathrm{MPa}$ (i.e. $f_{0.2,600} / f_{0.2 \text {,normal }}$ $=0.694)$, which was more than $2 / 3$ of that at ambient temperature, so WGJ steel was proved to be fire-resistant. At the same time, initial elastic modulus at $600^{\circ} \mathrm{C}$ was $162411 \mathrm{MPa}$ (i.e. $E_{600} / E_{\text {normal }}=0.826$ ), which was far more than $2 / 3$ of that at ambient temperature.

Reduction factor curves of $0.2 \%$ offset yield strength $\left(f_{0.2 \mathrm{~T}} / f_{0.2 \text { normal }}\right)$ obtained from this test program were compared with the formula recommended in AISC 360-10 [10], ASCE Manual [28], Australian Standard AS4100 [29] and Chinese Standard CECS 200:2006 [30], as shown in Figure 3. It can be seen that WGJ steel has higher yield strength than CSS at elevated temperatures, especially at temperature around $600^{\circ} \mathrm{C}$

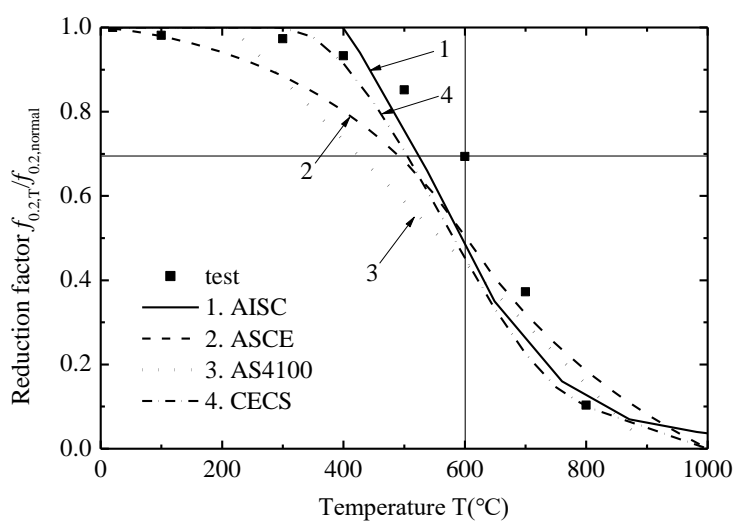

Fig. 3 Reduction factors of $0.2 \%$ offset yield strength in the test and specifications at different temperatures

Reduction factor curves of initial elastic modulus $\left(\mathrm{E}_{\mathrm{T}} / \mathrm{E}_{\text {normal }}\right)$ were also compared, as shown in Figure 4. It can be seen that WGJ steel has higher initial elastic modulus than CSS at elevated temperatures as well.

Since this paper emphasizes on the residual stress distribution of welded I sections, the material property and structural performance of WGJ steel under fire and corrosion conditions will not be discussed further. 


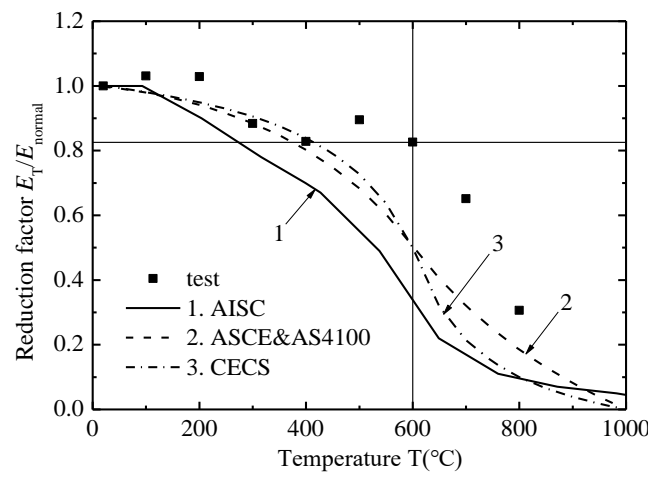

Fig. 4 Reduction factors of initial elastic modulus in the test and specifications at different temperatures

\subsection{Measuring residual stress by sectioning process}

The sectioning process was conducted following the guidance of Tebedge et al. [3]. A Wire-cut Electronic Discharge Machining (WEDM) was employed to reduce thermal effects. The strain values were calculated based on the deformation of strips which was measured by using YB-25 strain gage (as shown in Figure 5) before and after the sectioning process. The gauge length of YB-25 strain gage was $L_{0}=250 \mathrm{~mm}$ and the tolerance was $0.001 \mathrm{~mm}$.

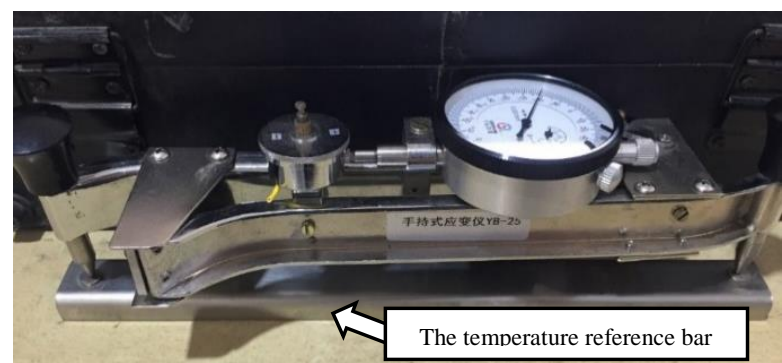

Fig. 5 YB-25 strain gage and the temperature reference bar

According to Tebedge et al. [3], tested segments should be selected more than 1.0 times of the section height $(\mathrm{H})$ away from both ends of members to reduce the end effects. In this experimental program, since the length of all specimens and strips was the same, the distances from the test segments to the ends were taken as $365 \mathrm{~mm}$, which was more than $1.0 \mathrm{H}$ for all three specimens RI1, RI2, RI3, respectively.

An example was given in Figure 6 for specimen RI1 to shown the sectioning arrangement. The length of strips was $270 \mathrm{~mm}$ and the distance of YB-25 gage holes was $250 \mathrm{~mm}$. As shown in the section view in Figure 6, the top and bottom flanges of RI1 were both cut into 15 strips with a width of $5 \mathrm{~mm}$ each, and the web was cut into 10 strips with a width of $10 \mathrm{~mm}$.

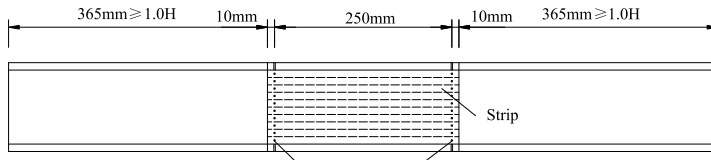

YB-25 gage holes

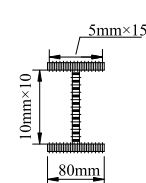

Fig. 6 Sectioning arrangement of RI

The sectioning process consisting of 3 steps is illustrated in Figure 7. Before sectioning, holes were drilled based on the arrangement shown in Figure 6, except some holes at the junction of the flange and web. Then the YB-25 strain gage was placed on each couple of holes to measure the initial gage length $r_{1}$. After that, the specimen was cut into segments by using the WEDM and the middle part was $270 \mathrm{~mm}$ long. The flanges and web were sliced further, and the holes had not be prepared before sectioning process could be drilled at this time. YB-25 strain gage was used to measure the distances of the holes drilled just now, and these values were also designated as $r_{1}$. The flanges and web were cut into strips and the distance between each couple of holes on the strip was measured by YB-25 strain gage and it was designated as $r_{3}$. The distance of holes on both sides of each strip was measured and recorded, and the average was taken for the subsequent analysis and modeling. The strips obtained from sectioning process are shown in Figure 8.

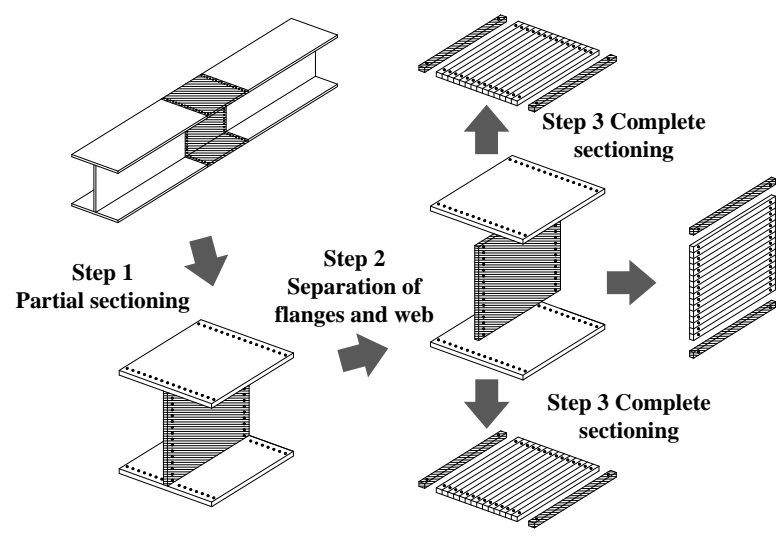

Fig. 7 Process of sectioning

In addition, bending deformation of strips should be measured and used to calibrate the results obtained from YB-25 strain gages. The bending deformation measurement is shown in Section 2.4. A reference bar for temperature compensation was applied to eliminate the error resulting from the temperature change during the test process.

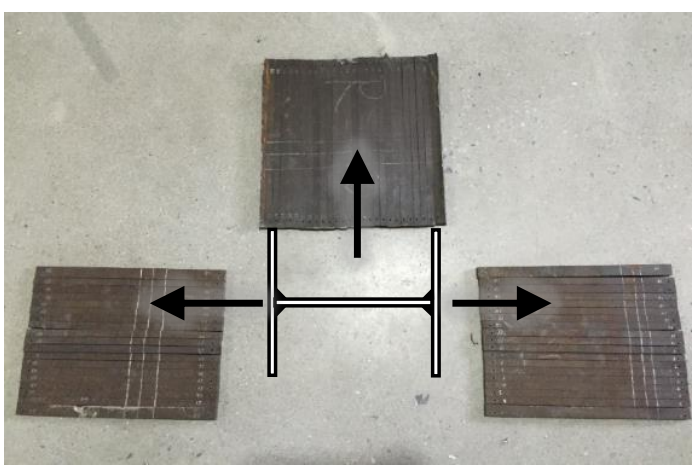

Fig. 8 Strips of RI3 after sectioning process

Residual strain can be obtained by comparing the initial reading $r_{1}$ prior to the sectioning process and the finial reading $r_{3}$ after sectioning. The residual strain can be calculated according to Eq. 1 .

$\varepsilon=\frac{\left(r_{3}+\Delta r_{t 3}\right)-\left(r_{1}+\Delta r_{t 1}\right)}{L_{0}+r_{1}+\Delta r_{t 1}}$

where $L_{0}$ is the gauge length of YB-25 strain gage and equals $250 \mathrm{~mm}$, $\Delta r_{\mathrm{ti}}(\mathrm{i}=1,3)$ is the reading of the temperature reference bar.

\subsection{Bending deformation measurement}

After sectioning, it was observed that some strips cambered out of straightness, especially those close to flame-cut edges and welding regions. Therefore, the measured value was the chord length rather than the arc length between two holes, so corrections should be incorporated in the calculation of residual strain.

As shown in Figure 9, a highly flat marble was employed as the reference plane, and a type of vertical caliper was applied to measure the offset of the strip.

Tebedge et al. [3] suggested a bending correction equation as given in Eq. 2. By moving the strip, the maximum offset was measured and designated as $\delta$ in this paper.

$\varepsilon_{r}=\varepsilon+\frac{(\delta / L)^{2}}{6(\delta / L)^{4}+1}$

where $\varepsilon_{\mathrm{r}}$ is the residual strain incorporating bending correction, and $L$ is the 
gauge length of YB-25 strain gage and equals $\left(L_{0}+r_{1}+\Delta r_{t 1}\right)$.

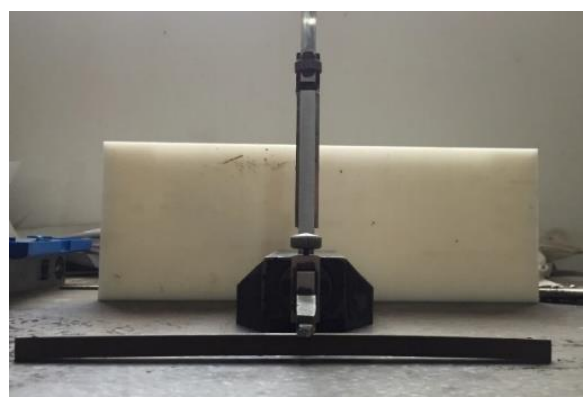

Fig. 9 Deformation measurement of a bending strip

Following the Hooke's Law, residual stress at the measured surface can be calculated as follows:

$\sigma_{r}=-E \cdot \varepsilon_{r}$

where $E$ is the Young's modulus of WGJ steel and taken as $E=196533 \mathrm{MPa}$ obtained from the material test results in this paper.

\section{Residual stress and analysis}

\subsection{Residual stress results}

In this experimental program, 3 specimens were cut into 155 strips in all and then more than 2000 data were recorded. Figure 10 summarizes the magnitude and distribution of residual stresses for each specimen. In these figures, compressive stress is negative while tensile stress is positive. Test results include measurements from both inside and outside surface of each strip and the average values are taken and presented in Figure 10.

The distribution pattern of residual stress for WGJ steel welded I sections is simplified as shown in Figure 11, which is similar to the distribution pattern for CSS as discussed in Section 1. Tensile residual stress was observed at weld regions and flange edges in Figure 11, while compressive residual stress was observed at middle regions of the steel plates. $\sigma_{\text {frt1 }}$ and $\sigma_{\text {frt2 }}$ represent the maximum values of tensile residual stress at welding regions of two flanges, while $\sigma_{\mathrm{wrt1}}$ and $\sigma_{\mathrm{wr} 2}$ represent the maximum stresses in the web. $\sigma_{\text {frii }}(\mathrm{i}=1,2,3,4)$ respectively denotes the maximum compressive residual stress in one of the four outstand flanges, while $\sigma_{\mathrm{wrc}}$ denotes the maximum one in the web. At last, $\sigma_{\text {frte }}$ (i=1,2,3,4) respectively denotes the maximum tensile residual stress at each flame-cut edge in the flange. These characteristic values are summarized in Table 2 .

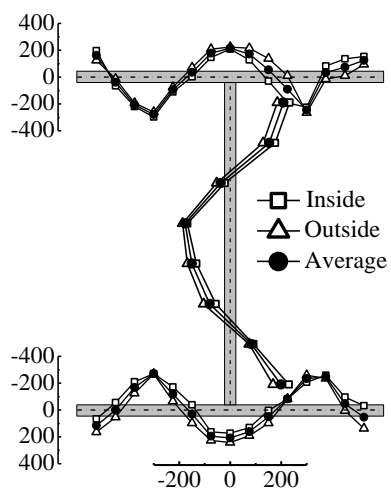

(a) RI1

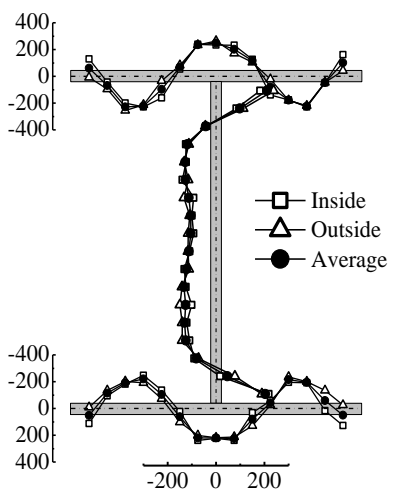

(b) RI2

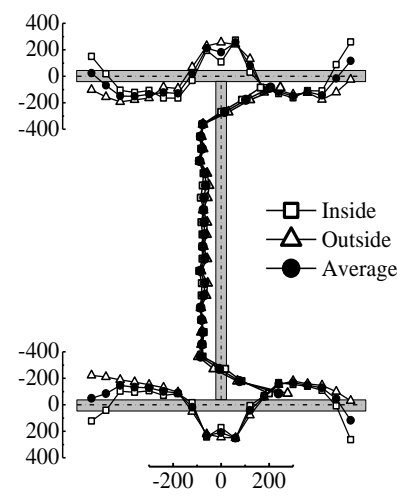

(c) RI3

Fig. 10 Residual stress for all sections (MPa), compressive stress in negative and tensile stress in positive

Table 2

Characteristic values of residual stress at typical locations

\begin{tabular}{|c|c|c|c|c|c|c|c|c|c|c|c|c|c|}
\hline & \multicolumn{10}{|c|}{ Results in flanges (MPa) } & \multicolumn{3}{|c|}{ Results in web (MPa) } \\
\hline & $\sigma_{\text {frcl }}$ & $\sigma_{\mathrm{frc} 2}$ & $\sigma_{\mathrm{frc} 3}$ & $\sigma_{\mathrm{frc4}}$ & $\sigma_{\mathrm{frt} 1}$ & $\sigma_{\mathrm{fft} 2}$ & $\sigma_{\text {frte } 1}$ & $\sigma_{\text {frte2 }}$ & $\sigma_{\text {frte3 }}$ & $\sigma_{\text {frte4 }}$ & $\sigma_{\mathrm{wrc}}$ & $\sigma_{\mathrm{wrt} 1}$ & $\sigma_{\mathrm{wrt} 2}$ \\
\hline RI1 & -278.7 & -245.9 & -270.1 & -247.3 & 215.8 & 207.8 & 160.8 & 123.7 & 116.3 & 53.2 & -177.3 & 199.1 & 208.6 \\
\hline RI2 & -228.4 & -224.0 & -219.3 & -215.0 & 249.1 & 225.4 & 60.6 & 101.4 & 51.7 & 51.1 & -132.9 & 203.5 & 210.2 \\
\hline RI3 & -151.0 & -150.0 & -145.4 & -166.5 & 256.2 & 252.2 & 23.8 & 116.8 & -48.9 & 117.1 & -89.5 & 238.6 & 206.1 \\
\hline
\end{tabular}

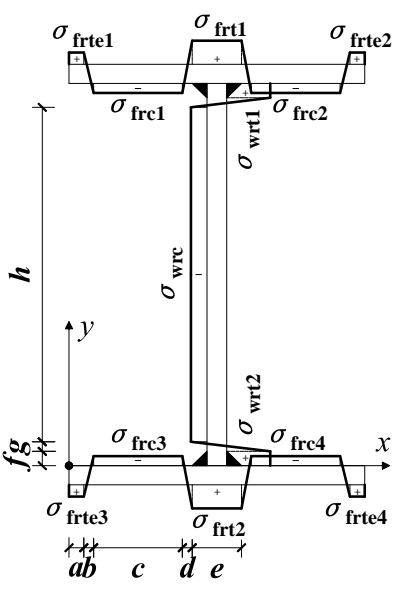

Fig. 11 Distribution and characteristic values of residual stress

\subsection{Effects of width-thickness ratio}

Magnitude of compressive and tensile residual stresses are given in Figure 12, where compressive stresses both in flanges and webs decrease monotonously as width-thickness ratios increase. This is because the residual stress after cooling process can be dispersed more effectively when the widththickness ratio is larger. Compressive stresses in flanges reduce more rapidly than those in webs.

Tensile stresses at welding regions in flanges vary slightly from $215.8 \mathrm{MPa}$ to $256.2 \mathrm{MPa}(256.2 / 215.8=1.19)$, and have no clear correlation with widththickness ratios. On the other hand, tensile stresses at flame-cut edges in flanges change more irregularly from $-48.9 \mathrm{MPa}$ to $123.7 \mathrm{MPa}$.

\subsection{Closing error}

Since there is no external force applied on tested segments, the closing error of residual stress over the whole cross section should be equal to zero to satisfy stress equilibrium. Thus, the closing error, defined by Eq. 4, can be used to verify the accuracy of test results. 
$\sigma_{\mathrm{err}}=\left[\sum_{i=1}^{n} A_{\mathrm{i}} \cdot \sigma_{\mathrm{ri}}\right] / \sum_{i=1}^{n} A_{\mathrm{i}}$

where $n$ is the number of strips, $A_{\mathrm{i}}$ is the sectional area of each strip, $\sigma_{\mathrm{ri}}$ is the residual stress magnitude of one strip.

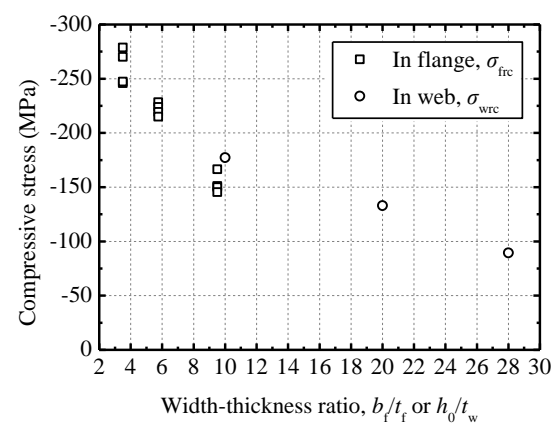

(a) Compressive residual stresses

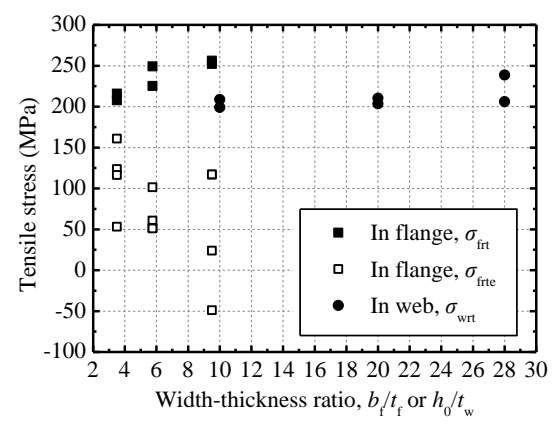

(b) Tensile residual stresses

Fig. 12 Relationship of residual stresses and width-thickness ratios

So as to investigate the relationship between residual stress in the flange and web, the closing error in each individual steel plate was obtained and shown in Figure 13. Figure 13 illustrates that the closing error of the whole section for RI1, RI2, or RI3 is no more than $\pm 30 \mathrm{MPa}$ (around $7 \%$ of $f_{0.2}$ ). It indicates that sections of all specimens are in stress equilibrium, and the test results of residual stress are correct.

With regard to the closing error in flanges, the maximum closing error is 27.2 MPa in top flanges, while -29.7 MPa in bottom flanges. In specimen RI2, the closing error in the web is $-55.9 \mathrm{MPa}$ (around $13 \%$ of $f_{0.2}$ ), which is the greatest value of closing error both in individual plates and in whole sections.

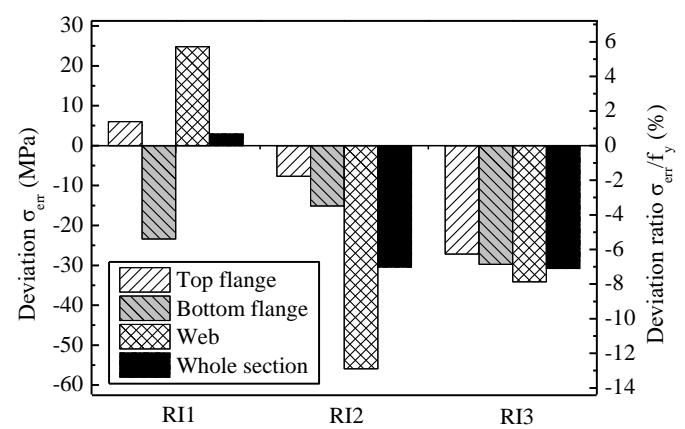

Fig. 13 Residual stress closing error of whole sections and individual parts

In summary, the stress equilibrium assumption is valid with the individual flanges and web for each specimen. In other words, residual stress in the flange is independent of that in the web.

\section{Modeling of residual stress for WGJ steel welded I sections}

\subsection{Existing residual stress distribution models}

Many distribution models of residual stress were proposed by other researchers, as shown Figure 14. Model (a) was proposed by Li et al. [31] and Model $(b)$ [12] was adopted in Chinese standard for the steel structure design GB 50017-2003 [11]. These two models are suggested for residual stress when designing steel columns under axial compression. Chernenko and Kennedy [6] proposed Model $(c)$ by studying former experimental data of CSS sections. These 3 models can be adopted when investigating flame-cut welded I sections fabricated from CSS, but may not be appropriate for HSS or HPS sections.

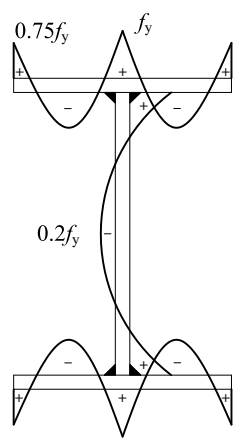

(a)

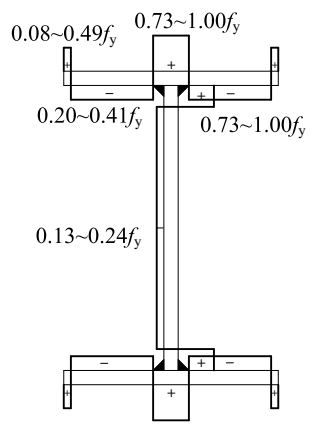

(d)

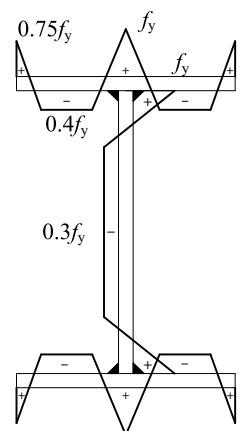

(b)

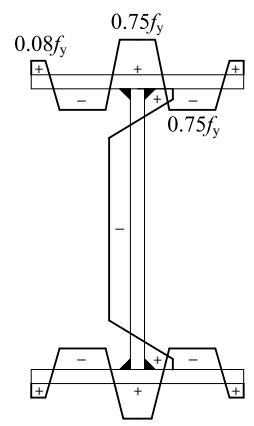

(e)

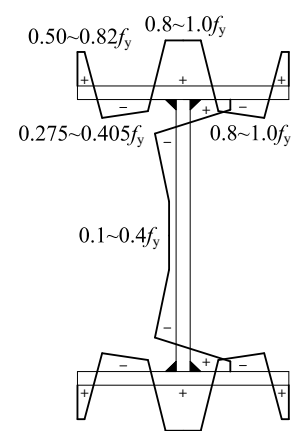

(c)

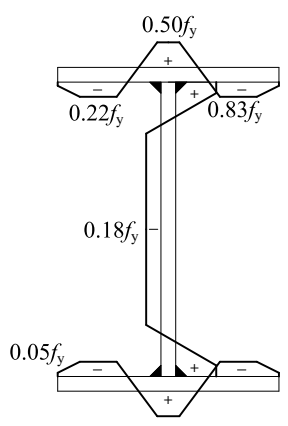

$(f)$

Fig. 14 Existing residual stress distribution models for flame-cut welded I sections 
Model (d) was presented in 2012 [17] based on the test of 3 flame-cut welded I section columns with a nominal yield strength of $460 \mathrm{MPa}$. Ban et al. [18] summarized previous research and proposed Model $(e)$ in 2013 based on original data measured from 8 I sections made of $460 \mathrm{MPa}$ steel. In Model (e), tensile stresses remain constant and compressive stresses are calculated according to the function of plate thickness and width-thickness ratio $\left(b_{\mathrm{f}} / t_{\mathrm{f}}\right.$, or $h_{0} / t_{\mathrm{w}}$ ). As for HPS sections, Yang et al. [23] suggested Model (f), which could be applied to describe the residual stress distribution of $460 \mathrm{MPa}$ GJ steel I sections.

Considering the special mechanical properties of WGJ steel, the distribution model of residual stress for WGJ steel I sections may be different from the existing models mentioned above.

\subsection{Proposed model}

WGJ steel is a new type of HPS with high strength, so Model $(d),(e)$ or $(f)$ may be possible solutions, while Model $(a),(b)$ and $(c)$ are suggested for CSS sections. However, tensile stresses at flange edges turn into compressive stresses discontinuously in Model $(d)$, which does not match the test results. In addition, in Model $(f)$, residual stresses at flange edges are negative, which does not match the test results observed in Section 3.1, either.

After examining the existing distribution models and the test results of residual stress, the distribution pattern characterized in Figure 11 or Model $(e)$ in Figure 14 was adopted in this paper to describe the residual stress of flamecut welded I sections fabricated of WGJ steel.

In Figure 11 or Model $(e)$, tensile stresses and compressive stresses in some regions remain constant ( $\sigma_{\mathrm{frt}}, \sigma_{\mathrm{frte}}, \sigma_{\mathrm{frc}}, \sigma_{\mathrm{wrt}}, \sigma_{\mathrm{wrc}}$ are constant values), and change linearly and continuously in other regions. Since the section referred in this paper is doubly symmetric and the section is in stress equilibrium, the residual stress distribution should be doubly symmetric as well. Thus, the characteristic values of residual stress at symmetric positions are the same $\left(\sigma_{\mathrm{frt1}-2}=\sigma_{\mathrm{frt}}, \sigma_{\mathrm{ftrel}}\right.$ $\left.{ }_{4}=\sigma_{\text {frte }}, \sigma_{\text {frcl- } 4}=\sigma_{\text {frc }}, \sigma_{\mathrm{wrtl}-2}=\sigma_{\mathrm{wrt}}\right)$.

According to the above discussion, the equations employed to quantify the residual stresses of welded I sections with WGJ steel are recommended as below.

$$
\sigma_{\text {fr }}(x)=\sigma_{\text {frt }}(B-x)= \begin{cases}\sigma_{\text {frte }} & 0 \leq x \leq a \\ \sigma_{\text {fre }}+\frac{\sigma_{\text {frc }}-\sigma_{\text {fre }}}{b}(x-a) & a<x \leq a+b \\ \sigma_{\text {frc }} & a+b<x \leq a+b+c \\ \sigma_{\text {frc }}+\frac{\sigma_{\text {frt }}-\sigma_{\text {frt }}}{d}[x-(a+b+c)] & a+b+c<x \leq a+b+c+d \\ \sigma_{\text {frt }} & a+b+c+d<x \leq a+b+c+d+e / 2\end{cases}
$$

$$
\sigma_{\mathrm{wr}}(y)=\sigma_{\mathrm{wr}}\left(h_{0}-y\right)= \begin{cases}\sigma_{\mathrm{wtr}} & 0 \leq y \leq f \\ \sigma_{\mathrm{wrt}}+\frac{\sigma_{\mathrm{wrc}}-\sigma_{\mathrm{wt}}}{g}(y-f) & f<y \leq f+g \\ \sigma_{\mathrm{wrc}} & f+g<y \leq f+g+h / 2\end{cases}
$$

where $\sigma_{\mathrm{fr}}$ is the residual stress at certain position $(x)$ in the flange, while $\sigma_{\mathrm{wr}}$ is the residual stress at certain position (y) in the web. Independent variable $x$ is the coordinate along the flange while $y$ is the one along the web, as shown in Figure 11. The geometrical symbols of $a$ to $h$ are illustrated in Figure 11 as well.

As shown in Figure 11, the following equations need to be met:

$a+b+c+d+e / 2=B / 2$

$f+g+h / 2=h_{0} / 2$

Since individual flanges and web for each specimen are in stress equilibrium, stresses in flanges $\sigma_{\mathrm{fr}}$ and stresses in the web $\sigma_{\mathrm{wr}}$ should comply with Eq. 9 and Eq. 10.

$\iint_{A_{\mathrm{f}}} \sigma_{\mathrm{fr}} d A=0$

$\iint_{A_{\mathrm{w}}} \sigma_{\mathrm{wr}} d A=0$

where $A_{\mathrm{f}}$ and $A_{\mathrm{w}}$ are areas of the flange and web respectively.

In this paper, only sections made of thin plates were investigated, so the variation of residual stress along thickness direction was not concerned. Thus, equations below can be derived from Eq. 9 and Eq. 10.

$\int_{B} \sigma_{\text {fr }}(x) d x=0$

$\int_{h_{0}} \sigma_{\mathrm{wr}}(y) d y=0$

\subsection{Parameters for tensile residual stress}

The experimental results of residual stresses in flanges and webs are summarized in Figure 15 and Figure 16 where the outstand plate is divided into 10 portions to describe the relative position of the measured data. According to the experimental results shown in Figure 10 and Table 2, maximum tensile residual stress $\sigma_{\text {frt }}$ ranges from 207.8 MPa to 256.2 MPa, corresponding to $48 \%$ to $59 \%$ of $0.2 \%$ offset yield strength $\left(f_{0.2}\right)$, which is $433.8 \mathrm{MPa}$ as obtained in Section 2.2. Therefore, $\sigma_{\text {frt }}$ is suggested as $260.3 \mathrm{MPa}, 60 \%$ of $f_{0.2}$, to cover all the measurement.

The tensile residual stress at the flame-cut edge varies from -48.9 MPa to $160.8 \mathrm{MPa}$, corresponding to $-11 \%$ to $37 \%$ of $0.2 \%$ offset yield strength $\left(f_{0.2}\right)$. Tensile stress at the flange edge is considered favorable for the stability of steel structure. Therefore, $\sigma_{\text {frte }}$ is suggested as the average value of the measurement, which is $75 \mathrm{MPa}$, or $17 \%$ of $f_{0.2}$.

Distribution parameters in the flange $(a, b, c, d, e)$ are identified based on Figure 15 and given in Table 3. The parameters $a, b$ and $e$ are constant, while $c$ and $d$ are determined according to Eq. 7 and Eq. 11 .

In Figure 16, maximum tensile residual stress $\sigma_{\text {wrt }}$ varies from $199.1 \mathrm{MPa}$ to $238.6 \mathrm{MPa}$, corresponding to $46 \%$ to $55 \%$ of $0.2 \%$ offset yield strength $\left(f_{0.2}\right)$. $\sigma_{\text {wrt }}$ is suggested as $238.6 \mathrm{MPa}$, or $55 \%$ of $f_{0.2}$, to cover all the measurement. Distribution parameters in the web $(f, g, h)$ are identified based on Figure 16 and given in Table 3. The parameter $f$ is constant, while $g$ and $h$ are determined according to Eq. 8 and Eq. 12.

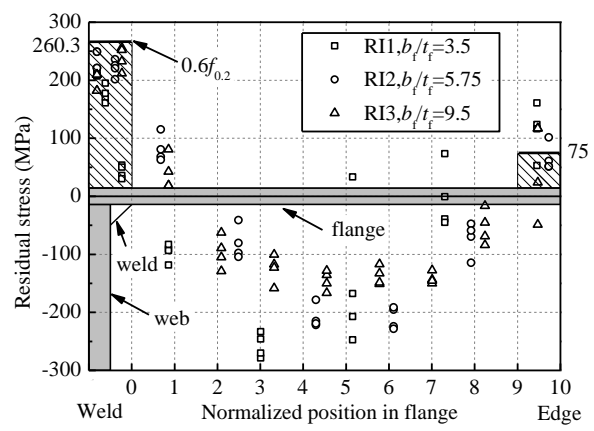

Fig. 15 Magnitude and distribution of residual stresses in the flange

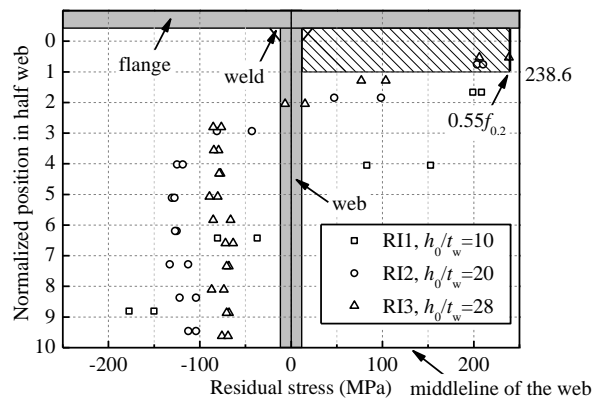

Fig. 16 Magnitude and distribution of residual stresses in the web

Table 3

Distribution parameters of the residual stress model

\begin{tabular}{cccc}
\hline$a$ & $b$ & $c$ & $d$ \\
\hline $0.1\left(b_{\mathrm{f}}-h_{\mathrm{f}}\right)$ & $0.2\left(b_{\mathrm{f}}-h_{\mathrm{f}}\right)$ & Eq. (7), (11) & Eq. (7), (11) \\
\hline$e$ & $f$ & $g$ & $h$ \\
\hline$t_{\mathrm{w}}+2 h_{\mathrm{f}}$ & $h_{\mathrm{f}+0.05\left(h_{0}-2 h_{\mathrm{f}}\right)}$ & Eq. (8), (12) & Eq. (8), (12) \\
\hline
\end{tabular}

4.4. Parameters for compressive residual stress

As discussed in Section 3.2, the magnitude of compressive residual stresses 
is affected by the width-thickness ratio $\left(b_{\mathrm{f}} / t_{\mathrm{f}}\right.$, or $\left.h_{0} / t_{\mathrm{w}}\right)$. It was also concluded by Ban et al. [18] that the magnitude of compressive residual stresses is also affected by the steel plate thickness $\left(t_{\mathrm{f}}\right.$, or $t_{\mathrm{w}}$ ). Therefore, two empirical fitting equations are proposed here and can be used to determine the compressive residual stress of welded I sections with WGJ steel:

$$
\left\{\begin{array}{l}
\sigma_{\mathrm{frc}}=\sigma_{\mathrm{fr} 0}+K_{\mathrm{fr} 1}\left(b_{\mathrm{f}} / t_{\mathrm{f}}\right)^{\alpha_{\mathrm{fr}}}+K_{\mathrm{fr} 2}\left(t_{\mathrm{f}}\right)^{\beta_{\mathrm{fr}}} \\
\sigma_{\mathrm{wrc}}=\sigma_{\mathrm{wr} 0}+K_{\mathrm{wr} 1}\left(h_{0} / t_{w}\right)^{\alpha_{\mathrm{wr}}}+K_{\mathrm{wr} 2}\left(t_{w}\right)^{\beta_{\mathrm{wr}}}
\end{array}\right.
$$

The coefficients in Eq. 13 , including $\sigma_{\mathrm{fr} 0}, \sigma_{\mathrm{wr} 0}, K_{\mathrm{fr} 1}, K_{\mathrm{fr} 2}, K_{\mathrm{wr} 1}, K_{\mathrm{wr} 2}, \alpha_{\mathrm{fr}}, \beta_{\mathrm{fr}}$, $\alpha_{\mathrm{wr}}, \beta_{\mathrm{wr}}$, were obtained from nonlinear fitting by using the general software Origin, based on the test results given in Table 2. The fitting result was shown in Eq. 14. It should be noted that the calculated results of compressive residual stress from the fitting equation Eq. 14 , where both $\sigma_{\text {frc }}$ and $\sigma_{\mathrm{wrc}}$, may be larger than $0.2 \%$ offset yield strength $\left(f_{0.2}\right)$ when width-thickness ratios are small. In case of this situation, the maximum magnitude of compressive residual stress should be limited to $f_{0.2}$.

$$
\begin{cases}\sigma_{\text {frc }}=1100-2890\left(b_{\mathrm{f}} / t_{\mathrm{f}}\right)^{-0.04}+170\left(t_{\mathrm{f}}\right)^{0.9} & \geq-f_{0.2}=-433.8 \\ \sigma_{\text {wrc }}=1790-5190\left(h_{0} / t_{w}\right)^{-0.015}+43500\left(t_{w}\right)^{-1.16} & \geq-f_{0.2}=-433.8\end{cases}
$$

However, Eq. 14 is still too complex for engineering application, and it is further simplified to Eq. 15, which can clearly describe the increasing trend of compressive residual stresses as width-thickness ratios $\left(b_{\mathrm{f}} / t_{\mathrm{f}}, h_{0} / t_{\mathrm{w}}\right)$ and steel plate thickness $\left(t_{\mathrm{f}}, t_{\mathrm{w}}\right)$ decrease

Coefficients $\alpha_{\mathrm{fr}}, \beta_{\mathrm{fr}}, \alpha_{\mathrm{wr}}, \beta_{\mathrm{wr}}$ are taken as -1.0 in Eq. 15. The other coefficients in Eq. 15 , including $\sigma_{\mathrm{fr} 0}, \sigma_{\mathrm{wr} 0}, K_{\mathrm{fr} 1}, K_{\mathrm{fr} 2}, K_{\mathrm{wr} 1}, K_{\mathrm{wr} 2}$ are determined in the similar way through nonlinear fitting based on the test results given in Table 2 .

$$
\begin{cases}\sigma_{\text {frc }}=50-570 \times \frac{1}{b_{\mathrm{f}} / t_{\mathrm{f}}}-1570 \times \frac{1}{t_{\mathrm{f}}} & \geq-f_{0.2}=-433.8 \\ \sigma_{\mathrm{wrc}}=120-1140 \times \frac{1}{h_{0} / t_{w}}-1840 \times \frac{1}{t_{w}} & \geq-f_{0.2}=-433.8\end{cases}
$$

\section{Table 4}

\begin{tabular}{|c|c|c|c|c|c|c|c|c|}
\hline $\begin{array}{l}\mathrm{La}- \\
\text { bel }\end{array}$ & $\begin{array}{c}\sigma_{\text {frc.f }} \\
(\mathrm{MPa})\end{array}$ & $\sigma_{\mathrm{frc}, \mathrm{f}} / \sigma_{\mathrm{frc}, \mathrm{t}}$ & $\begin{array}{c}\sigma_{\mathrm{frc}, \mathrm{fs}} \\
(\mathrm{MPa}) \\
\end{array}$ & $\sigma_{\mathrm{frc}, \mathrm{fs}} / \sigma_{\mathrm{frc}, \mathrm{t}}$ & $\begin{array}{r}\sigma_{\text {wrc,f }} \\
(\mathrm{MPa}) \\
\end{array}$ & $\sigma_{\mathrm{wrc}, f} / \sigma_{\mathrm{wrc}, \mathrm{t}}$ & $\begin{array}{c}\sigma_{\text {wr.,fs }} \\
(\mathrm{MPa}) \\
\end{array}$ & $\sigma_{\mathrm{wrc}, \mathrm{fs}} / \sigma_{\mathrm{wrc}, \mathrm{t}}$ \\
\hline RI1 & -298.4 & 1.145 & -269.9 & 1.036 & -214.3 & 1.209 & -178.0 & 1.004 \\
\hline RI2 & -244.3 & 1.102 & -206.1 & 0.930 & -162.5 & 1.223 & -121.0 & 0.911 \\
\hline RI3 & -190.8 & 1.245 & -167.0 & 1.090 & -137.5 & 1.537 & -104.7 & 1.171 \\
\hline
\end{tabular}

Compressive residual stresses obtained from proposed equations and comparison with test results

where $\sigma_{\text {frc,f }}$ and $\sigma_{\text {wr.f }}$ denote compressive residual stresses in flanges and webs determined by the fitting equation Eq. 14 respectively. $\sigma_{\mathrm{frc}, \mathrm{t}}$ and $\sigma_{\mathrm{wrc}, \mathrm{t}}$ represent the test results of compressive residual stresses in flanges and webs, respectively. $\sigma_{\mathrm{frc}, \mathrm{fs}}$ and $\sigma_{\mathrm{wrc}, \mathrm{fs}}$ denote compressive residual stresses in flanges and webs determined by the simplified fitting equation Eq. 15 respectively.

\subsection{Model validation}

Based on the model given in Section 4.2 and parameters determined in Section 4.3 and Section 4.4, the modeling results of residual stress are obtained and illustrated in Figure 17 with black solid lines. Notice that the compressive stresses ( $\sigma \mathrm{frc}$ and $\sigma \mathrm{wrc}$ ) applied in this model are identified by the simplified fitting equation Eq. 15 and shown in Table 4. It is found that the modeling results are in good agreement with the test results. The validation indicates that the proposed model in this paper can be employed to identify the magnitude and distribution of residual stresses for WGJ steel flame-cut welded I sections.

It should be noted that the results of this investigation are only applicable to steel members with special material properties, limited shape and dimensions of the section, and specific welding and manufacturing process. More theoretical and experimental researches are in need to confirm and improve the proposed modeling approach.
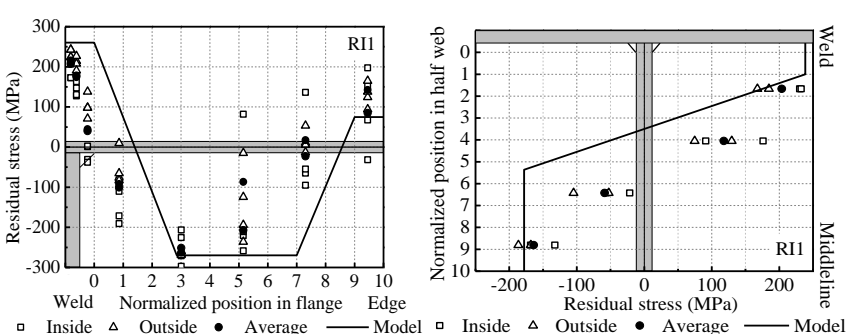

(a) RI1
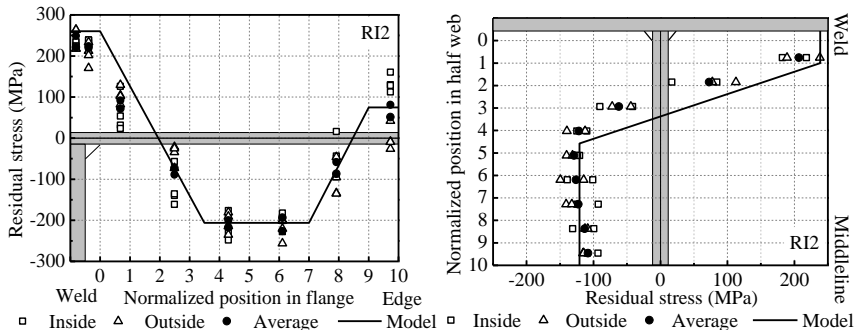

- Inside $\Delta$ Outside $\bullet$ Average - Model $\square$ Inside $\Delta$ Outside $\bullet$ Average - Mode

(b) RI2
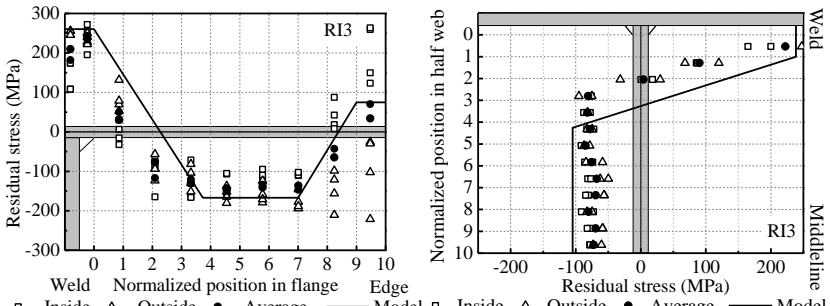

Inside $\Delta$ Outside $\bullet$ Average - Model $\square$ Inside $\Delta$ Outside $\bullet$ Average - Model

(c) RI3

Fig. 17 Comparison of proposed model with experimental results

\subsection{Analysis of the magnitude of residual stress}

Ban [19] proposed a versatile model to estimate the magnitude and distribution of residual stresses, which was applicable to welded I sections and box sections fabricated from steel with various strength. Table 5 and Figure 18 compared the calculating results of residual stresses for specimen RI1, RI2 and RI3 based on the proposed model by Ban and the proposed model in this paper, respectively.

It is observed that for every specimen, the magnitude of tensile stress (i.e. $\left.\sigma_{\mathrm{frt}}, \sigma_{\mathrm{wrt}}\right)$ and compressive stress (i.e. $\sigma_{\mathrm{frc}}, \sigma_{\mathrm{wrc}}$ ) given by Ban's model are larger than those given by the proposed model in this paper. This is mainly because these two models are applicable to different types of steel. Ban's model is for HSS sections, while the proposed model in this paper is for WGJ steel sections. So it can be concluded that when applying WGJ steel in manufacturing flamecut welded I sections, the residual stresses can be reduced to some extent.

Table 5

Characteristic values of residual stress obtained from Ban (2012) and this paper

\begin{tabular}{ccccccccc}
\hline Label & \multicolumn{3}{c}{ Proposed model by Ban $(2012)$} & \multicolumn{3}{c}{ Proposed model in this paper } \\
\cline { 2 - 8 } & $\begin{array}{c}\sigma_{\text {frt }} \\
(\mathrm{MPa})\end{array}$ & $\begin{array}{c}\sigma_{\text {wrt }} \\
(\mathrm{MPa})\end{array}$ & $\begin{array}{c}\sigma_{\text {frc }} \\
(\mathrm{MPa})\end{array}$ & $\begin{array}{c}\sigma_{\text {wrc }} \\
(\mathrm{MPa})\end{array}$ & $\begin{array}{c}\sigma_{\mathrm{frt}} \\
(\mathrm{MPa})\end{array}$ & $\begin{array}{c}\sigma_{\text {wrt }} \\
(\mathrm{MPa})\end{array}$ & $\begin{array}{c}\sigma_{\text {frc }} \\
(\mathrm{MPa})\end{array}$ & $\begin{array}{c}\sigma_{\text {wrc }} \\
(\mathrm{MPa})\end{array}$ \\
\hline RI1 & 345 & 345 & -386.2 & -266.0 & 260.3 & 238.6 & -269.9 & -178.0 \\
RI2 & 345 & 345 & -282.2 & -156.0 & 260.3 & 238.6 & -206.1 & -121.0 \\
RI3 & 345 & 345 & -218.4 & -124.6 & 260.3 & 238.6 & -167.0 & -104.7 \\
\hline
\end{tabular}

Residual stress is associated with the non-uniform plastic deformation in a rather narrow weld zone which is restrained by the rest of the plate. During the welding process, the welding region is heated while strength and elastic modulus of steel decrease rapidly, so the plastic deformation is more likely to happen. As shown in Figure 19, because of the higher strength and stiffness of WGJ steel at high temperature when welding (detailed mechanical properties can be observed in the test results mentioned in Section 2.2), plastic strain at weld regions of the WGJ steel section under certain thermal stress $\sigma_{\mathrm{T} 0}$ (caused by non-uniform heat) is less than that of the HSS or CSS section. As a result, 
the residual deformation and residual stress at welding regions of the WGJ steel section after cooling may be much less. Since the tensile residual stress is reduced, the compressive residual stress decreases as well because of stress equilibrium.

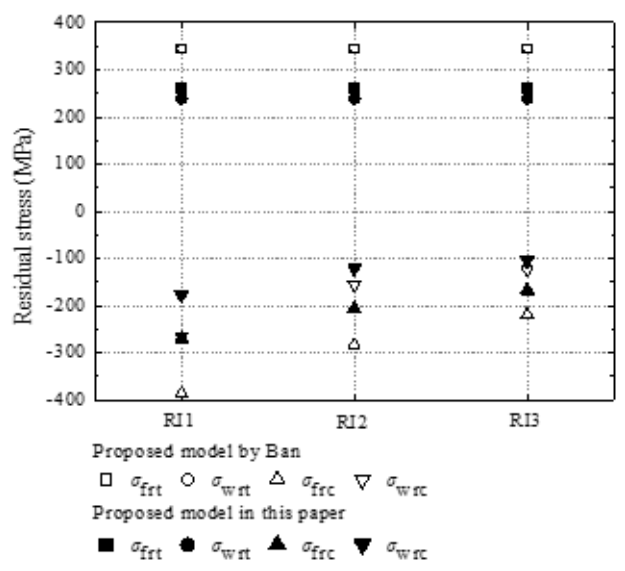

Fig. 18 Comparison of residual stresses obtained from Ban (2012) and this paper

The explanation above just gives one possible reason why residual stresses are reduced when applying welded I sections fabricated of WGJ steel. Further study should be conducted on this topic.

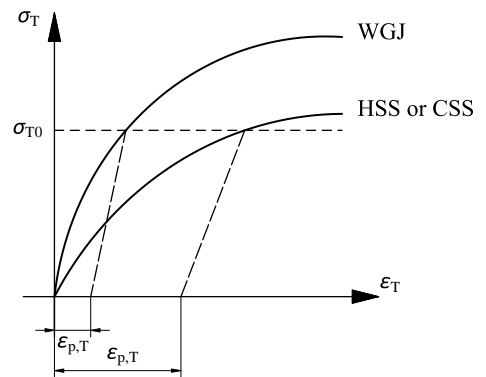

Fig. 18 Stress-strain curves for HSS, CSS and WGJ steel at high temperature

\section{Conclusions}

The residual stress in flame-cut welded I sections fabricated from a new type of HPS, designated as WGJ steel, were investigated in this experimental program. The sectioning method was applied to cut the plates into strips. Residual strain was measured by using YB-25 strain gage. Based on the experimental measurement and analysis on the effects of sectional dimensions and interactions between flanges and webs, a distribution model of residual stress was proposed and validated through experimental results. Based on this work, the following conclusions can be drawn:

1. The distribution pattern of residual stress for WGJ steel welded I sections was similar to that for HSS or HPS I sections, but the magnitude of tensile residual stresses and compressive residual stresses was quite different.

2. Compressive stresses both in flanges and webs decreased monotonously as the width-thickness ratios increased. In addition, the residual stresses in flanges were not related to those in webs.

3. Maximum tensile residual stresses at welding regions in both flanges and webs for WGJ steel were much lower than the steel yield strength (for WGJ

\section{Acknowledgement}

The authors gratefully acknowledge the financial supports from the National Natural Science Foundation of China (No. 51578313). Thanks are also extended to Beijing Innovation Center for Metropolitan Transportation for the research facilities provided. The test material and specimens provided by Wuhan Iron and Steel (Group) Company are highly appreciated.

\section{References}

[1] Wang G.Z. and Qu L.Q., "Steel Structure: Principle and Design", Tsinghua University Press, Beijing, China, 1993. (in Chinese).

[2] Alpsten G.A. and Tall L., "Residual stresses in heavy welded shapes", Welding Journal, 49(3), 93-105, 1970.
[3] Tebedge N., Alpsten G. and Tall L., "Residual-stress measurement by the sectioning method", Experimental Mechanics, 13(2), 88-96, 1973.

[4] Fukumoto Y. and Itoh Y., "Statistical study of experiments on welded beams", Journal of the Structural Division, ASCE, 107(1), 89-103, 1981.

[5] Wang G.Z. and Zhao W.W., "Residual stress measurement for welded and hot-rolled section steels", Industrial Construction, 16(7), 32-37, 1986. (in Chinese).

[6] Chernenko D.E. and Kennedy D.J.L., "An analysis of the performance of welded wide flange columns", Canadian Journal of Civil Engineering, 18(14), 537-555, 1991.

[7] Goto Y. and Kawanishi N., "Change of weld residual stresses due to loss of material", Journal of Structural Engineering, 132(12), 1940-1947, 2006.

[8] British Standards Institution, Eurocode 3: Design of Steel Structures: Part 1-1: Genera Rules and Rules for Buildings, EN 1993-1-1, 2005.

[9] European Convention for Constructional Steelworks, Manual on Stability of Steel Structures: Part 2.2: Mechanical Properties and Residual Stresses, Second Edition. ECCS Publ., 1976.

[10] American Institute of Steel Construction, Specification for Structural Steel Buildings, ANSI/AISC 360-10, Chicago, 2010.

[11] Ministry of Housing and Urban-Rural Development, Code for Design of Steel Structures, GB 50017-2003, China Planning Press, China, 2003 (in Chinese).

[12] Code for Design of Steel Structures Committee, Application Construal of Code for Design of Steel Structures in China, China Planning Press, China, 2003 (in Chinese).

[13] Shi G., Ban H.Y., Shi Y.J. and Wang Y.Q. "Recent research advances on high strength and high performance steel structures in Tsinghua University", Proceedings of the 6th International Symposium on Steel Structures (ISSS-2011), Seoul, Korea, 984-991, 2011.

[14] Rasmussen K.J.R. and Hancock G.J., "Plate slenderness limits for high strength steel sections", Journal of Constructional Steel Research, 23(1), 73-96, 1992.

[15] Rasmussen K.J.R. and Hancock G.J., "Tests of high strength steel columns", Journal of Constructional Steel Research, 34(1), 27-52, 1995.

[16] Beg D. and Hladnik L., "Slenderness limit of class 3 I cross-sections made of high strength steel", Journal of Constructional Steel Research, 38(8), 201-217, 1996.

[17] Wang Y.B., Li G.Q. and Chen S.W., "Residual stresses in welded flame-cut high strength steel H-sections", Journal of Constructional Steel Research, 79(12), 159-165, 2012.

[18] Ban H.Y., Shi G., Bai Y., Shi Y.J. and Wang Y.Q., "Residual stress of $460 \mathrm{MPa}$ high strength steel welded I section: Experimental investigation and modeling”, International Journal of Steel Structures, 13(4), 691-705, 2013.

[19] Ban H.Y., "Research on the Overall Buckling Behavior and Design Method of High Strength Steel Columns under Axial Compression", PhD thesis, Tsinghua University, Beijing China, 2012 (in Chinese)

[20] Chen J., "Measurement and Analysis on Residual Stress in Welded I-shaped Crosssectional Member", MS thesis, Chongqing University, Chongqing, China, 2010 (in Chinese).

[21] Yang B., Nie S.D., Kang S.B., Xiong G., Hu Y., Bai J.B., Zhang W.F. and Dai G.X., "Residual Stress Measurement on Welded Q345GJ Steel H-Section by Sectioning Method and Method Improvement", Advanced Steel Construction, 13(1), 78-95, 2017.

[22] Qiu L.B., Xue S.D., Hou Z.X., Liu Y, and Shu G.P., "Experimental study of residua stresses in Q550GJ high-strength steel welded H-type sections", Journal of Beijing University of Technology, 41(7), 1035-1042, 2015. (in Chinese)

[23] Yang B., Nie S.D., Xiong G., Hu Y., Bai J.B., Zhang W.F. and Dai G.X., "Residual stresses in welded I-shaped sections fabricated from Q460GJ structural steel plates", Journal of Constructional Steel Research, 122, 261-273, 2016.

[24] Li T.J., Liu S.W. and Chan S.L., "Cross-sectional analysis of arbitrary sections allowing for residual stresses", Steel \& Composite Structures, 18(4), 985-1000, 2015.

[25] Li T.J., Liu S.W. and Chan S.L., "Direct analysis for high-strength steel frames with explicit-model of residual stresses", Engineering Structures, 100, 342-355.

[26] Standardization Administration of China, Metallic materials - tensile testing - Part 2 Method of test at elevated temperature, GB/T 228.2-2015, Beijing, Standards Press of China, 2015. (in Chinese).

[27] Wang Y.Q., Wang Z.X., Hu X.G., Han J.K. and Xing H.J., "Experimental study and parametric analysis on the stability behavior of 7A04 high-strength aluminum alloy angle columns under axial compression", Thin-Walled Structures, 108, 305-320, 2016.

[28] American Society of Civil Engineers, Structural Fire Protection, ASCE Manual and Reports on Engineering Practice No. 78, New York, 1992.

[29] Australia Standards, Steel Structures, AS 4100:1998, Sydney, Australia, 1998.

[30] China Association for Engineering Construction Standardization, Technical Code for Fire Safety of Steel Structure in Buildings, CECS 200:2006, China Planning Press, China, (in Chinese).

[31] Li K.X., Xiao Y.H., Nao X.F., Cui J. and Zhu W., "Column curves for steel compression member", Journal of Chongqing Architecture University, 1, 24-33, 1985. (in Chinese) 